\title{
Direito sobre biografias no Brasil
}

\author{
Gustavo Tepedino*
}

\section{Opinião doutrinária}

Honra-nos ORGANIZAÇÕES GLOBO, por meio do conceituado escritório Binenbojm, Gama \& Carvalho Britto Advocacia, solicitando OPINIÃO DOUTRINÁRIA acerca da interpretação conforme a Constituição da República dos arts. 20 e 21 do Código Civil.

A Consulente formula o seguinte quesito:

À luz do ordenamento jurídico-constitucional brasileiro, a publicação ou veiculação de obras biográficas, literárias ou audiovisuais, de pessoas públicas, ou pessoas envolvidas em acontecimentos de interesse público, depende da autorização das pessoas biografadas ou envolvidas de qualquer forma na obra biográfica (ou de seus familiares, em caso de pessoas falecidas)?

Para responder a tal indagação, elaborou-se a presente OPINIÃO DOUTRINÁRIA, cujas conclusões se encontram abaixo sintetizadas, seguindo-se seu desenvolvimento e a resposta objetiva ao quesito formulado.

\footnotetext{
* Professor titular de direito civil da Faculdade de Direito da Universidade do Estado do Rio de Janeiro (Uerj). Doutor em direito civil pela Universidade de Camerino (itália). Professor visitante das Universidades de lvfolise (Itália); São Francisco (Califórnia, EUA); e Poitiers (França); pesquisador visitante do Instituto Max Planck de Direito Privado Comparado e Internacional (Hamburgo, Alemanha). Membro da Academia Internacional de Direito Comparado e da Academia Brasileira de Letras Jurídicas.
} 
Síntese: Os arts. 20 e 21 do Código Civil, ao tutelarem a imagem, a privacidade e a honra das pessoas, hão de ser interpretados em conformidade com a Constituição da República, de modo a não sacrificar o direito fundamental à informação e às liberdades de expressão e de pensamento. Exclui-se assim, por inconstitucional, qualquer interpretação daqueles dispositivos legais que proíba as obras biográficas, literárias ou audiovisuais, de pessoas notórias, sem prévia autorização dos biografados ou de seus familiares na hipótese de pessoa falecida. As biografias, com efeito, revelam narrativas históricas descritas a partir de referências subjetivas, isto é, do ponto de vista dos protagonistas dos fatos que integram a história. Tais fatos, só por serem considerados históricos, já revelam seu interesse público, em favor da liberdade de informar e de ser informado, da memória e da identidade cultural da sociedade.

Os homens públicos que, por assim dizer, protagonizam a história, ao assumirem posição de visibilidade, inserem voluntariamente a sua vida pessoal e o controle de seus dados pessoais no curso da historiografia social, expondo-se ao relato histórico e a biografias. Qualquer condicionamento de obras biográficas ao consentimento do biografado, ou de seus familiares em caso de pessoas falecidas, sacrifica, conceitualmente, o direito fundamental à (livre divulgação de) informação, por estabelecer seleção subjetiva de fatos a serem divulgados, em sacrifício das liberdades de expressão e de pensamento e em censura de elementos indesejados pelo biografado. Há incongruência lógica, teleológica, dogmática e sistemática entre as liberdades de expressão e de pensamento e a escolha de fatos a serem admitidos em obras biográficas. A ponderação prévia e in abstracto entre o direito fundamental à informação e as liberdades de expressão e de pensamento, de um lado, e, de outro lado, a proteção à imagem, honra, privacidade e intimidade do biografado não pode importar em sacrifício das primeiras, sob pena de se consagrar censura privada e a extinção do gênero biografia. Eventual dano causado pela informação de fato considerado histórico não é ressarcível. Ainda que prejudicial à personalidade do biografado, trata-se de dano que não pode ser considerado injusto, e, portanto, indenizável, por decorrer do exercício regular e legítimo das liberdades de expressão, de informação e de pensamento, asseguradas pelo Texto Constitucional. 
O abuso ou desvio do exercício da liberdade de informação, caracterizado pela ilicitude das fontes, falsidade evidente dos fatos apresentados ou desvirtuamento da finalidade do interesse tutelado é severamente punido pelo ordenamento, após juízo a posteriori (jamais a priori, mediante ponderação in abstracto que, in casu, constituiria censura privada, em constrangedora incompatibilidade com o texto constitucional), capaz de configurar tipos penais (calúnia, injúria, difamação, prática de racismo, falsidade ideológica etc.). Por evidente, conforme precedentemente decidido pelo Supremo Tribunal Federal, coibida seria a obra que, sob aparente conteúdo informativo, revelasse intuito imoral, criminoso ou doloso contra a honra, intimidade ou imagem do biografado. Tal reação do ordenamento, no campo da responsabilidade civil, não decorre do impacto negativo causado pela notícia histórica na personalidade do biografado, ainda que tal fato the seja efetivamente desgostoso e sofrido, mas somente do desvirtuamento da liberdade de expressão, que caracterizaria mentira ou desinformação, a configurar invariavelmente conduta abusiva.

\section{Os arts. 20 e 21 do Código Civil e sua interpretação conforme a Constituição da República. As biografias como relato histórico a dispensar autorização dos biografados ou de seus familiares, em caso de pessoas falecidas. A tutela constitucional das liberdades de expressão, de informação e do pensamento ao lado da proteção constitucional da imagem, honra, intimidade e privacidade.}

1. Mostra-se de todos conhecida a redação do caput do art. 20 do Código Civil:

Art. 20. Salvo se autorizadas, ou se necessárias à administração da justiça ou à manutenção da ordem pública, a divulgação de escritos, a transmissão da palavra, ou a publicação, a exposição ou a utilização da imagem de uma pessoa poderão ser proibidas, a seu requerimento e sem prejuízo da indenização que couber, se lhe atingirem a honra, a boa fama ou a respeitabilidade, ou se se destinarem a fins comerciais.

2. A linguagem do preceito não é feliz. Destinado a abrigar contemporaneamente diversos interesses, acaba por suscitar controvérsia interpretativa, 
permitindo leitura equivocada que, em nome de atributos da personalidade - notadamente a imagem, a intimidade, a honra e a privacidade - , sacrifica o direito fundamental à liberdade de expressão, de pensamento e à informação.

3. A dicção literal desse dispositivo, associada ao disposto no art. 21 do Código Civil, que autoriza ao juiz a cessar ameaças à privacidade, atribuiria ao magistrado o poder de proibir, mediante valoração subjetiva, a divulgação de qualquer informação que potencialmente pudesse prejudicar a privacidade, aniquiland o o trabalho jornalístico e a publicação de biografias, condicionadas ao prévio assentimento do biografado ou de seus familiares, na hipótese de pessoa falecida. Examine-se o teor do art. 21 do Código Civil:

Art. 21. A vida privada da pessoa natural é inviolável, e o juiz, a requerimento do interessado, adotará as providências necessárias para impedir ou fazer cessar ato contrário a esta norma.

4. Tanto as liberdades de informação e de expressão como a tutela à imagem, à honra, à intimidade e à privacidade, expressões da personalidade humana, encontram-se constitucionalmente inseridas no rol das garantias fundamentais estabelecidas no art. 5, IV, IX, X e XIV, da Constituição da República, in verbis:

Art. 5으. (...)

IV - é livre a manifestação do pensamento, sendo vedado o anonimato;

IX - é livre a expressão da atividade intelectual, artística, científica e de comunicação, independentemente de censura ou licença;

X - são invioláveis a intimidade, a vida privada, a honra e a imagem das pessoas, assegurado o direito a indenização pelo dano material ou moral decorrente de sua violação;

XIV - é assegurado a todos o acesso à informação e resguardado o sigilo da fonte, quando necessário ao exercício profissional;

5. Não bastasse a garantia como liberdade fundamental, o direito à informação e as liberdades de expressão e de pensamento encontram-se previstos no art. 220 da Constituição da República, de maneira ostensivamente reiterada e ampla: 
Art. 220. A manifestação do pensamento, a criação, a expressão e a informação, sob qualquer forma, processo ou veículo não sofrerão qualquer restrição, observado o disposto nesta Constituição.

$\S 1^{\circ}$ - Nenhuma lei conterá dispositivo que possa constituir embaraço à plena liberdade de informação jornalística em qualquer veículo de comunicação social, observado o disposto no art. 5, IV, V, X, XIII e XIV. $\S 2^{2} \mathrm{o}-$ É vedada toda e qualquer censura de natureza política, ideológica e artística.

6. Desse conjunto de preceitos normativos extrai-se que os arts. 20 e 21 do Código Civil, ao tutelarem a imagem, a intimidade, a privacidade e a honra, consideradas emanações da personalidade humana, não podem amesquinhar "a manifestação do pensamento, a criação, a expressão e a informação" e nem se constituir em "embaraço à plena liberdade de informação", tampouco em "censura de natureza política, ideológica e artística", terminantemente vedada pelo $\S 2$, art. 220 .

7. Eis o que pretendeu o constituinte, concedendo às liberdades de expressão, pensamento e de informação posição de destaque, justificada historicamente em nome da consolidação do Estado Democrático de Direito, desenhado pelo constituinte e definitivamente proclamado pelo Supremo Tribunal Federal no histórico julgamento que baniu a Lei no 5.250, de 9 de fevereiro de 1967, a chamada Lei de Imprensa.

8. Naquela ocasião, estatuiu-se que:

a Constituição brasileira se posiciona diante de bens jurídicos de personalidade para, de imediato, cravar uma primazia ou precedência: a das liberdades de pensamento e de expressão lato sensu (que ainda abarca todas as modalidades de criação e de acesso à informação, esta última em sua tríplice compostura, conforme reiteradamente explicitado). Liberdades que não podem arredar pé ou sofrer antecipado controle nem mesmo por força do Direito-lei, compreensivo este das próprias emendas à Constituição, frise-se. ${ }^{1}$

\footnotetext{
${ }^{1}$ STF. ADPF 130/DF, Tribunal Pleno, rel. min. Carlos Ayres Britto, julg. 30.4.2009.
} 
9. Do ponto de vista do direito civil, desviriliza-se todo o conjunto das garantias constitucionais à livre informação caso se pretendesse compreender os arts. 20 e 21 do Código Civil como limites preestabelecidos às manifestações de pensamento, condicionando-se as informações jornalísticas e as biografias, mercê de leitura literal das regras infraconstitucionais, à autorização de todos aqueles cuja personalidade, direta ou indiretamente, viesse a ser atingida.

10. Em consequência, acabar-se-ia por banir, por ilegal, as obras biográficas que, retratando fatos históricos, viessem a alcançar aspectos da vida privada de pessoas notórias ou expostas, por sua trajetória, à vida pública, sem a prévia autorização destas ou de seus familiares, no caso de pessoas falecidas.

11. Tal interpretação, posto que incompatível com o sistema, seduz por vez alguns civilistas por dois motivos fundamentais. Em primeiro lugar, voltase, aparentemente, para a maior proteção dos chamados direitos da personalidade, sem que se tenha em mente que a liberdade de manifestação de pensamento é também inerente à personalidade humana e sua restrição, portanto, tolhe a vida digna. Sem liberdade de informar e ser informado não há dignidade da pessoa humana. ${ }^{2}$ Tal assertiva torna-se dramaticamente grave quando se leva em conta o passado autoritário que antecedeu a Constituição de 5 de outubro de 1988 na experiência brasileira.

12. Além disso, a personalidade humana, no âmbito do direito civil, ainda recebe tratamento hermenêutico influenciado pelo modelo das relações patrimoniais, especialmente pelo direito proprietário, que serve de paradigma para a teoria dos direitos subjetivos. ${ }^{3}$ Em consequência, protege-se a

\footnotetext{
${ }^{2}$ Na síntese de Pietro Perlingieri, "Informazione, personalità e democrazia appaiono valori indissolubilmente connessi" (Manuale di diritto privato. Napoli: Edizione Scientifiche Italiane, 1997. p. 161).

${ }^{3}$ Diversos autores, na esteira dessa concepção patrimonialista dominante no direito civil do século XIX, refutaram a categoria dos direitos da personalidade justamente por se revelarem incompatíveis com a noção de direito subjetivo, construindo as denominadas teorias negativistas. V., por todos, ENNECCERUS, L.; KIPP, T.; WOLFF, M. Tratado de derecho civil: parte general. Barcelona: Bosch, 1944. t. I, v. 1, p. 289 e 307. Para uma crítica a essa tendência de patrimonialização da tutela da personalidade, sob o paradigma do direito subjetivo de propriedade, v. TEPEDINO, Gustavo. A tutela do personalidade no ordenamento civil constitucional brasileiro. In: Temas de direito civil. 4. ed. rev. e atual. Rio de Janeiro: Renovar, 2008. p. 25 e ss, e esp. p. 32, quando se observa, criticamente, no que tange à construção histórica dos chamados direitos de personalidade, que "a própria validade da categoria parecia depender da individuação de um bem jurídico elemento objetivo da relação jurídica - que não se confundisse com a pessoa humana - elemento subjetivo da relação jurídica - , já que as utilidades sobre as quais incidem os interesses patrimoniais do indivíduo, em particular no direito dominical, lhe são sempre exteriores". Compreende-se,
} 
privacidade como território encastelado em si mesmo, tendo por parâmetro a inviolabilidade do domicílio. ${ }^{4}$

\section{São numerosos os exemplos dessa concepção de proteção da personalidade na jurisprudência brasileira e também norte-americana, onde ainda prevalece, para a proteção da privacy, a invocação do precedente do trespass (que consagra a inviolabilidade da propriedade alheia) como critério definidor dos limites de tutela da privacidade. ${ }^{5}$}

14. Tal perspectiva influenciou sobremaneira a dogmática da personalidade nos países de tradição romano-germânica, que somente no século XX desenvolveram a noção de intimidade, construída a partir do "right to be let alone", forjado nos Estados Unidos pelo famoso ensaio de Samuel Warren e Louis Brandeis. ${ }^{6}$

assim, a perspectiva seguida, em página clássica, por Francesco Ferrara, para quem tais direitos absolutos da personalidade "têm por conteúdo a pretensão de exigir respeito de tais bens pessoais. A vida, o corpo, a honra são o ponto de referenda (termine di riferimento) da obrigação negativa que incumbe à coletividade" (Trattato di diritto civile italiano. Dottrine generali. Roma: Athenaeum, 1921. v. 1, p. 395).

${ }^{4}$ V., sobre o tema, LAFER, Celso. A reconstrução dos direitos humanos: um diálogo com o pensamento de Hannah Arendt. São Paulo: Companhia das Letras, 1988. p. 240, o qual registra que "a construção doutrinária e pretoriana em torno do direito à intimidade (...) tem como ponto de partida o tema clássico da inviolabilidade de domicílio". V. tb. DONEDA, Danilo. Da privacidade à proteção de dados pessoais. Rio de Janeiro: Renovar, 2006. p. 7 e ss., o qual passa em revista os diversos conceitos de privacidade até a sua configuração atual.

${ }^{5}$ Eloquente, a este propósito, recente julgamento do Caso United States v. Jones, no $10-1259$, District of Columbia Circuit, january 23, 2012 (In: <www.supremecourt.gov/opinions/11pdf/10-1259.pdf>. Acesso em: 5 jun. 2012), em que a Suprema Cone declarou inconstitucional, por violação da $4^{\mathrm{a}}$ Emenda, a instalação de GPS no carro do réu, invalidando, assim, investigação criminal que resultou na prisão de importante traficante de drogas. A argumentação majoritária inclinouse pela invocação do common-law trespass test, já que o dispositivo eletrônico fora inserido no automóvel do réu quando estacionado na frente de sua residência. Em contrapartida, o voto do Justice Sotomayor discordou desse entendimento, afirmando que questões como esta deveriam ser submetidas exclusivamente ao procedente de Katz v. U.S. (n. 389 U.S., p. 347), que associa a tutela da 4 a emenda ao critério da "reasonable expectation of privacy". O acalorado debate em torno do critério de proteção da privacy pode ser sintetizado no seguinte trecho da ementa da decisão: "The conclusion is consistent with this Court's Fourth Amendment jurisprudence, which until the latter half of the 20th century was tied to common-law trespass. Later cases, which have deviated from that exclusively property-based approach, have applied the analysis of Justice Harlan's concurrence in Katz v. United States, 389 U.S 347, which said that the Fourth Amendment protects a person's 'reasonable expectation of privacy' (..) The Katz reasonableexpectation-of-privacy test has been added to, but not substituted for, the common-law trespassory test".

${ }^{6}$ The right to privacy. Harvard Law Review, v. IV, n. 193, 15 dez. 1890. O ensaio decorreu, certamente, do incômodo sentido por Warren em razão das recorrentes notícias acerca das recepções realizadas por sua mulher em espaços privados do casal. Sua concepção de privacidade, atrelada ao esquema proprietário, é bem definida por Rodotà: "non si entra nella proprietà, non si entra nella vita privata" (Intervista su privacy e libertà. Roma: Editori Laterza, 2005. p. 8). 
15. Para o direito civil contemporâneo, em contrapartida, deve-se compreender a privacidade não mais como o direito estático de estar só, senão em perfil dinâmico, despida do paradigma da propriedade, concebida agora como o "controle das informações pessoais" ou a "possibilidade de um sujeito conhecer, controlar, direcionar ou mesmo interromper o fluxo de informações que lhe dizem respeito". ${ }^{7}$

16. A noção há de ser bilateralmente dinâmica. Funciona tanto para o controle dos dados pessoais pelo próprio interessado na sociedade da informação, ${ }^{8}$ em que bancos de dados circulam entre fornecedores contendo dados sensíveis dos consumidores ou empregados, como para assegurar o direito de acesso à informação biográfica que, oriunda da trajetória de vida de uma pessoa pública, se confunde com a realidade histórica da sociedade. Significa dizer que, com a voluntária exposição à vida pública ou a cenários de dimensão pública, a pessoa expõe seus dados pessoais, ate então recônditos, oferecendoos ao interesse coletivo, tornando-os notícia ou fato histórico de interesse público.

17. Em contexto assim estabelecido, não cabe ao intérprete procurar identificar, na dimensão pública em que os fatos históricos se sucedem, os aspectos não noticiáveis, porque contidos na propriedade do seu autor, já que emanados da personalidade de seu titular, tratando a imagem, à semelhança do tratamento por muito tempo reservado ao direito autoral, como ativo individual, pela avaliação econômica que tais elementos existenciais representam. ${ }^{9}$ Semelhante elaboração teórica influenciou a malsinada redação da parte final do caput do

\footnotetext{
${ }^{7}$ RODOTA, Stefano. Tecnologie e diritti. Bologna: Il Mulino, 1995. p. 122.

${ }^{8}$ Sobre $a$ sociedade da informação, v. LYON, David. The roofs of the information society idea. In: SULLIVAN, Tim O'; JEWKES, Yvonne (Ed.). The media studies reader. Londres: Arnold, 1998. p. 384-402. Ao propósito, Rodota observa o direito de privacidade do eixo "pessoa-informaçãosegredo" para o eixo "pessoa-informação-circulação-controle" (Tecnologie e diritti, op. cit., p. 102). 9 A imagem, compreendida como ativo economicamente apreciável, sujeito a precificação, circunscreveria sua proteção ao poder concedido para a sua exploração, pelo titular ou por terceiros mediante sua autorização, em lógica proprietária incompatível com os direitos da personalidade. Cf., sobre o ponto, BITTAR, Carlos Alberto. Direitos da personalidade. Rio de Janeiro: Forense Universitária, 1989. p. 87-89: "Essa disponibilidade permite ao titular extrair proveito econômico do uso de sua imagem, ou de seus componentes, mediante contratos próprios, firmados com os interessados, em que autorizam a prévia fixação do bem almejado (...) Constituem, assim, atos ilícitos, não só o uso não consentido, como também o uso que extrapole os limites contratuais (em finalidade diversa, ou não expressamente ajustada), em qualquer situação em que seja colhida, ou fixada a pessoa, para posterior divulgação, com ou sem finalidade econômica".
} 
art. 20 do Código Civil, cuja dicção textual coíbe a finalidade comercial do uso da imagem, daí se extraindo imediatamente a violação a personalidade. Preocupa-se, assim, o dispositivo, aos moldes das relações patrimoniais, não com a qualidade dos dados divulgados e sua função, mas em afastar pura e simplesmente o aproveitamento econômico de bem alheio.

18. As biografias revelam relatos históricos descritos a partir de referências subjetivas, isto é, do ponto de vista dos principais protagonistas da cadeia de eventos cronológicos que integram a história. Tais eventos, só por serem considerados históricos, revelam seu interesse público, em favor da liberdade de informar e de ser informado, essencial não somente como garantia individual, mas como preservação da memória e da identidade cultural da sociedade.

19. Os homens públicos, que se destacam na história, ao assumirem posição de visibilidade, inserem voluntariamente a sua vida pessoal e o controle de seus dados pessoais no curso da historiografia social, expondo-se ao relato contido nas biografias.

20. Qualquer condicionamento de obras biográficas ao consentimento do biografado (ou de seus familiares na hipótese de pessoa falecida) sacrifica, conceitualmente, o direito fundamental à (livre divulgação de) informação, por estabelecer seleção subjetiva de fatos a serem divulgados, em sacrifício das liberdades de expressão e de pensamento e em censura privada de elementos indesejados pelo biografado. Dito por outras palavras, não há como se pretender, baseado em padrões abstratos de hábitos ou condutas (a inquebrantável standard do bom pai de família?), distinguir o que seria fato suscetível de ser divulgado daquele que, ao reverso, por suas nuances comportamentais, não poderia ser publicado.

21. Como contar a história do primeiro reinado sem levar em conta as relações extraconjugais do imperador, relevantes para a compreensão dos costumes da época, das ligações entre a burguesia e a nobreza, do método de nomeação das autoridades e cargos públicos e assim por diante? Seria razoável condicionar a divulgação de cartas e documentos que retratam fielmente o relacionamento do imperador com suas amantes e a imperatriz à autorização dos descendentes da nobiliarquia brasileira? Seria possível cogitar-se de liberdade de expressão sem a ampla permissão constitucional para a publicação de tais biografias? 
22. O exemplo mostra-se bastante ilustrativo, já que provavelmente ninguém na historiografia nacional teve sua intimidade mais devassada do que o cidadão Pedro de Alcântara Francisco, Antonio João Carlos Xavier de Paula, Miguel Rafael, Joaquim Jose, Gonzaga Pascoal, Cipriano Serafim de Bragança e Bourbon, justamente pela notabilíssima posição pública por ele ocupada, a partir da qual sua vida privada - e inevitavelmente a sua intimidade se interpolam com a vida das nações que governou: o Brasil, como Pedro I, e Portugal, como Pedro IV. Curiosamente, somente a ampla divulgação dos fatos ditos íntimos permitiu que, biografia atrás de biografia, publicação após publicação, se superassem os boatos, os mexericos e se pudessem, finalmente, relativizar os fatos, contextualizando-os, graças ao trabalho sério de historiadores e pesquisadores, nos costumes e cultura do Brasil imperial. Aliás, diga-se entre parênteses, os fatos que se pretendem, em geral, retirar de biografias, permanecem como obscuros rumores, difundidos amplamente pela internet e mediante publicações acéfalas, causando, aí sim, dano significativo à personalidade dos interessados, por sua imprecisão histórica e irresponsabilidade própria do anonimato de quem as divulga.

23. Não ha dúvida de que, para as descendentes de dom Pedro I, possa ser chocante ler - se quiserem fazê-lo, é claro, como é próprio das democracias - os relatos acima aludidos. Mas os possíveis danos que lhe são causados com a penosa leitura não são ressarcíveis, já que expressão das liberdades de informação e de pensamento em torno de fatos de interesse público. E, por maioria desta razão, tais biografias não poderiam ser impedidas ou retiradas de circulação por força da intervenção dos descendentes do biografado.

24. Vale dizer, ao contrário do que apregoa candidamente a primeira parte do art. 21 do Código Civil, a privacidade da pessoa natural é violada a todo momento; é invadida diuturnamente na convivência social. E assim o é tomando de empréstimo a metáfora imortalizada pelo clássico romance de Daniel Defoe - desde que o nativo Sexta-Feira apareceu na ilha para Robson Crusoé. Trata-se, isto sim, de definir os limites de tolerabilidade e a origem das invasões de privacidade legítimas, as quais serão merecedoras de tutela, por exemplo, quando traduzem o direito de informar fatos tidos consistentemente como verdadeiros, de interesse público, de pessoas que, por sua notoriedade, fazem-se biografadas.

25. Nessa linha de raciocínio, tem-se que os danos sofridos pela personalidade dos biografados e de seus descendentes, quando a biografia se circunscreve aos 
limites de legitimidade próprios da informação constitucionalmente tutelada, isto é, quando baseada em fatos obtidos por fontes legítimas e sem intuito abusivo ou doloso, não configuram danos ressarcíveis ou aptos a suscitarem a tutela preventiva de que cuidam os arts. 20 e 21 do Código Civi1. ${ }^{10}$

26. Se a informação for inverossímil ou obtida de fonte ilícita, ou destinada a escopo ilícito, há incidência do óbice previsto pelo art. 20, do Código Civil, justificando-se somente nestas hipóteses a repressão a notícias motivadas pelos fins comerciais a que se destinam, pressupondo aqui o intérprete a desnaturação da finalidade informativa. Nestes casos, não somente caberá indenização cabal como poderá haver tipificação de crime, como ocorre nas notícias que caracterizam injúria, calúnia e difamação. ${ }^{11}$

27. Na experiência brasileira, o Plenário do Supremo Tribunal Federal teve ocasião de julgar caso emblemático, denegando o writ no Habeas Corpus n. 82.424-2 RS, impetrado pelo editor Siegfried Ellwanger, cujas publicações

\footnotetext{
${ }^{10}$ Em hipótese de veiculação de notícia acerca do suposto envolvimento, em fato criminoso, de certo indivíduo, posteriormente considerado inocente, ponderou a ministra Nancy Andrighi que as liberdades de informação e expressão se sobreporiam aos direitos da personalidade do indivíduo, considerando o interesse público a informação e a busca de fontes fidedignas pelos jornalistas, em raciocínio por tudo aplicável à publicação de biografias: "A honra e imagem dos cidadãos não são violadas quando se divulgam informaçães verdadeiras e fidedignas a seu respeito e que, além disso, são do interesse público. O veículo de comunicação exime-se de culpa quando busca fontes fidedignas, quando exerce atividade investigativa, ouve as diversas partes interessadas e afasta quaisquer dúvidas sérias quanto à veracidade do que divulgará. O jornalista tem um dever de investigar os fatos que deseja publicar. Isso não significa que sua cognição deva ser plena e exauriente À semelhança daquilo que ocorre em juízo. A elaboração de reportagens pode durar horas ou meses, dependendo de sua complexidade, mas não se pode exigir que a mídia só divulgue fatos após ter certeza plena de sua veracidade. Isso se dá, em primeiro lugar, porque os meios de comunicação, como qualquer outro particular, não detêm poderes estatais para empreender tal cognição. Ademais, impor tal exigência à imprensa significaria engessá-la e condená-la à morte. O processo de divulgação de informações satisfaz verdadeiro interesse público, devendo ser célere e eficaz, razão pela qual não o se coaduna com rigorismos próprios de um procedimento judicial. A reportagem da recorrente indicou o recorrido como suspeito de integrar organização criminosa. Para sustentar tal afirmação, trouxe ao ar elementos importantes, como o depoimento de fontes fidedignas (...) Não se tratava, portanto, de um mexerico, fofoca ou boato que, negligentemente, se divulgava em cadeia nacional. A suspeita que recaía sabre o recorrido, por mais dolorosa que lhe seja, de fato, existia e era, à época, fidedigna. Se hoje já não pesam sabre o recorrido essas suspeitas, isso não faz com que o passado se altere. Pensar de modo contrário seria impor indenização a todo veículo de imprensa que divulgue investigação ou ação penal que, ao final, se mostre improcedente" (STJ. REsp. 984.803, 3 T., rel. min. Nancy Andrighi, julg. 26.5.2009; grifou-se).

${ }^{11}$ A Lei de Imprensa enumerava os tipos penais nos arts. 14 a 22, consistentes, fundamentalmente, na divulgação de notícias falsas ou fatos verdadeiros deturpados, que provocassem os efeitos enumerados na lei; ofensa à moral ou aos bons costumes; calúnia, injúria e difamação. Com a não recepção da Lei de Imprensa pela Constituição de 1988, por meio do julgamento da ADPF no 130 , tais crimes passaram ser regulados pelo Código Penal e Código de Processo Penal.
} 
antissemitas foram tipificadas como crime de racismo (art. 20, Lei 7.716/89, com a redação dada pela Lei 8.091/90), inafiançável e imprescritível, segundo preceitua o art. 5ㅇ, XLI1, C.R. Tendo-se em conta que a manifestação de pensamento é livre, e que se constitui em direito fundamental o acesso a todo tipo de obra, mesmo aquelas que professam ideologias abjetas, o controle judicial acerca da atividade nefasta do paciente não poderia jamais ser efetuado a priori ou in abstracto. Deu-se justamente a posteriori e in concreto, quando foi constatada que a atividade editorial camuflava o propósito criminoso do editor, tornando suas publicações, por via oblíqua, arauto da prática de racismo.

28. Destaque-se, no julgamento, trecho do voto do Ministro Marco Aurélio:

não é correto se fazer um exame entre liberdade de expressão e proteção da dignidade humana de forma abstrata e se tentar extrair daí uma regra geral. (...) A limitação estatal à liberdade de expressão deve ser entendida com caráter de extrema excepcionalidade e há de ocorrer apenas quando sustentada por claros indícios de que houve um grave abuso no exercício. ${ }^{12}$

29. E, ainda, passagem do voto do Ministro Celso de Mello:

Semelhante procedimento estatal, que implicasse verificação prévia do conteúdo das publicações, traduziria ato inerentemente injusto, arbitrário e discriminatório. Uma sociedade democrática e livre não pode institucionalizar essa verificação prévia do Estado, nem admiti-la como expediente dissimulado pela falsa roupagem do cumprimento e da observância da Constituição. (...) Os abusos no exercício da liberdade de manifestação do pensamento, quando praticados, legitimarão sempre "a posteriori", a reação estatal, expondo aqueles que os praticarem a sanções jurídicas, de índole penal ou de caráter civil. ${ }^{13}$

\footnotetext{
12 STF, HC 82.424, rel. min. Moreira Alves, rel. p/ acórdão min. Mauricio Correa, julg. 17.9.2003.

${ }^{13}$ STF. HC 82.424, Tribunal Pleno, rel. min. Moreira Alves, Rel. IV acórdão min. Mauricio Corrêa, julg. 17.9.2003. Vale conferir também trecho do voto do ministro Ayres Britto: "o que a Lei das Leis garante a cada ser humano é um espaço apriorístico de movimentação: o uso da respectiva autonomia da vontade para exteriorização do pensamento (vedado tão somente o anonimato) e da atividade artística, estética, científica e de comunicação. O abuso e o agravo são questões que apenas a posteriori se colocam. E para combatê-los é que a Lei Republicana prevê dois dispositivos específicos: a) o inciso $\mathrm{V}$ do art. $5^{\circ}(.$.$) ; b) o inciso X do mesmo art. 5^{\circ}$ (...) Agravo e abuso passam a
} 
30. A decisão do STF demonstra que a liberdade de expressão jamais pode ser previamente tolhida e que, quando abusiva, se ocultar propósitos criminosos, estes serão desvendados, voltando-se o Judiciário, de forma rigorosíssima (o crime é inafiançável e imprescritível!), para a repressão da conduta nociva.

\section{O caso em análise é mesmo paradigmático: estivesse o senhor Ellwanger} no exercício regular da atividade editorial, sem o propósito criminoso, suas publicações seriam legítimas ainda que ferissem, por seu conteúdo, a personalidade daqueles diretamente atingidos pelo preconceito, ou, pior, daqueles que sofreram, na própria carne, a ação hedionda do nazismo. Nos limites da liberdade de expressão, os danos que aqui fossem perpetrados não seriam considerados, tecnicamente, injustos ${ }_{1}^{14}$ sendo certo que o deplorável livro de Adolf Hitler, Mein Kampf, se encontra disponível nas livrarias nacionais, traduzido provavelmente em todos os idiomas dos países democráticos.

32. Na vida cotidiana, a personalidade humana é atingida rotineiramente, sem que haja dano ressarcível. A cobrança de dívida pode levar o devedor insolvente à depressão profunda e até mesmo ao suicídio, sem que haja aí, tecnicamente, dano injusto provocado pelo credor. No âmbito das relações

ser ventilados, portanto, já no plano de reação de outrem; sendo que o agravo suscita o exercício de um direito de resposta que nem depende de processo de apuração de transbordamento da originária autonomia da vontade. Um transbordamento que se é transbordamento por violar uma outra e alheia autonomia de vontade, também juridicamente prezada. Mas a premissa da Constituição é uma só: não é pela possibilidade de agravo a terceiros, ou de uso invasor da liberdade alheia, que se vai coibir a primitiva liberdade de expressão (que se define, assim, como liberdade absoluta, nesse plano da incontrolabilidade da sua apriorística manifestação)".

${ }^{14}$ A noção de dano injusto tem se afirmado, na dogmática do sistema romano germânico, como sendo os danos que, por opção legislativa, se afiguram ressarcíveis. Como assinala Renato Scognamiglio: "Certo que esta reação do direito, que assinala a transferência do dano de um sujeito a outro, não pode operar nos confrontos de todos os prejuízos, e tendo-se em conta a gravidade das consequências para o lesado. Deve tratar-se, na verdade, de um dano reputado relevante pelo mesmo ordenamento jurídico, ao êxito da valoração dos interesses e exigências dos sujeitos que se encontram em conflito. Mas tal discriminação ocorre, e isto constitui um argumento decisivo e ulterior, sobre o mesmo plano de identificação do prejuízo, segundo o seu conteúdo e direção (os bens-interesses que são atingidos); para o qual coerentemente o direito vigente requer a conotação de injustiça (Responsabilità civile. Novissimo digesto, v. XV, Torino: UTET, 1968, p. 638; tradução livre). No original: "Certo questa reazione del diritto, che segna il trasferimento del donna do un soggetto all'altro, non può operare nei confronti di tutti $i$ pregiudizi, e semmai tenendo conto della gravita delle conseguenze per il leso. Deve trattarsi invero di un danno reputato rilevante dallo stesso ordinamento giuridico, all'esito della valutazione degli interessi ed esigenze dei soggetti che si trovano in conflitto. Ma una siffatta discriminazione avviene, e questa costituisce un ulteriore quanta decisivo argomento, sullo stesso piano dell'identificazione del pregiudizio, secondo il suo contenuto e direzione $i$ beni-interessi che vengono colpiti); per cui coerentemente il diritto vigente postula il connotato dell'ingiustizia". 
afetivas, bastaria pensar no fim de um relacionamento amoroso, como ocorre na ruptura unilateral de noivado, por exemplo, em que não há dano injusto, inexistindo, portanto, dever de reparação, ainda que a dor possa ser lancinante, com evidente dano à personalidade causado pela separação. Haverá nesses casos dano moral ressarcível somente quando, no contexto in concreto, houver ilicitude na conduta, humilhação propriamente dita imposta por um nubente ao outro, ou pelo credor ao devedor e assim por diante. O dano decorre da caracterização de ato ilícito, não da ruptura em si considerada. ${ }^{15}$

\section{No âmbito das atividades jornalísticas, revelam-se numerosas as hipóteses} nas quais o exercício das liberdades de informação e de expressão atinge a personalidade do retratado, sem, contudo, causar dano injusto, precisamente por veicular notícias sérias, de interesse público, relacionadas a pessoas notórias, sem o intuito de ofender, de modo a configurar exercício regular de direito, em preponderância das liberdades sobre a personalidade do indivíduo. ${ }^{16}$

\footnotetext{
${ }^{15}$ Ao propósito, sublinha Maria Celina Bodin de Moraes: “O pleno e amplo exercício do princípio da liberdade de casar - decorrência direta e inelutável do direito fundamental de liberdade não pode ser sopesado desfavoravelmente em relação à quebra do compromisso pré-nupcial, ato perfeitamente lícito no ordenamento jurídico nacional" (MORAES, Maria Celina Bodin de. Honra, liberdade de expressão e ponderação. In: FRAZÃO, Ana; TEPEDINO, Gustavo (Coord.). O Superior Tribunal de Justiça e a reconstrução do direito privado. São Paulo: Revista dos Tribunais, 2011. p. 608).

${ }^{16}$ Sobre o tema, a jurisprudência do Superior Tribunal de Jurisprudência é ampla. Cf., a título ilustrativo, os seguintes precedentes: STJ, REsp. 1201688, $3^{\text {a }}$ T., rel. min. Massami Uyeda. Rel. p/ acórdão min. Sidnei Beneti, julg. 23.6.2009; STJ, Resp. 984803, 3a T., rel. min. Nancy Andrighi, julg. 26.5.2009; STJ, REsp. 253058, 4ª T., rel. min. Fernando Gonçalves, julg. 4.2.2010. Na jurisprudência italiana, atualmente, em linha evolutiva, com base no art. 97 da Lei 633/41, tem-se admitido a prevalência da liberdade de expressão dos meios de comunicação relativamente à privacidade do indivíduo quando a informação divulgada é verdadeira, de interesse público com escopo didático ou cultural, e sem o intuito de ofender o retratado. Como assinalado em doutrina: "Existem, portanto, no caso concreto, dois interesses em conflito, ambos de relevância constitucional: de um lado, o direito da atriz a não ver divulgadas notícias relativas à sua esfera privada; do outro, o direito de transitar livremente o próprio pensamento e, assim, o direito de informar e de ser informado através do livre exercício da crônica, também televisiva. Quando existe um conflito entre tais interesses contrapostos, segundo a jurisprudência, considera-se prevalente o direito à crônica quando haja relevância social da notícia, e, portanto, o interesse geral de ser informado, quando a notícia seja verdadeira e não seja veiculada de modo ofensivo" (SEVERE, Antonio; CERRI, Augusto. Il diritto di informazione e i diritti della persona - il conflitto della libertà di pensiero con l'onore, la riservatezza, l'identità personale. In: Teoria e pratica del diritto, sez. III 73. Milão: Giuffre Editore, 2006. p. 117-120; tradução livre). No original: "Vi sono, quindi, nel caso concreto, due interessi in conflitto, entrambi di rilevanza costituzionale: da un lato il diritto dell' atrice a non vedere divulgate notizie relative alla sua sfera privata, dall'altro diritto di manifestare liberamente il proprio pensiero e quindi il diritto ad informare e ad essere informal attraverso il libero esercizio della cronaca, anche televisiva. Quando esiste un conflitto tra tali interessi contrapposti, secondo la giurisprudenza, va considerato prevalente il diritto di cronaca quando vi sia la rilevanza sociale della notizia, e quindi l'interesse generale ad esserne informati, quando tale notizia sia vera e quando essa non venga esposta in modo di per se offensivo".
} 
34. Em posição análoga, pode-se concluir que as biografias não autorizadas de pessoas notórias, só por si, não geram danos ressarcíveis, traduzindo o direito constitucional a livre manifestação do pensamento e informação que, como tais, não podem ser impedidas, coibidas ou cerceadas, ${ }^{17}$ nem devem se sujeitar à precificação patrimonialista pretendida por alguns herdeiros em casos notórios. ${ }^{18}$

35. Os abusos na editoração de obras criminosas, em que a publicação deixa de ser informativa, pela ilicitude de sua origem ou de seus propósitos nocivos, notadamente a veiculação de fatos mentirosos, com o propósito de causar danos ao biografado, certamente contêm as únicas hipóteses fáticas em que os arts. 20 e 21 se mostram consentâneos com o Texto Constitucional. Nesses casos, de informação já não se trata, deflagrando-se a repressão penal e civil não pelo dano causado à personalidade por conta da publicação de fatos íntimos (estes danos não seriam injustos) senão pela desinformação levada a cabo a pretexto de exercício de atividade editorial.

36. Há, portanto, incongruência lógica, teleológica, dogmática e sistemática entre as liberdades de expressão, de pensamento e de informação e a escolha de fatos a serem admitidos em obras biográficas. Incongruência lógica porque o discrime entre o publicável e o não publicável é incompatível com o próprio conceito das liberdades de expressão, de pensamento e de informação;

\footnotetext{
${ }^{17}$ Vale registrar que mesmo o chamado direito ao esquecimento, invocado como forma de apagar parcela da vida ou fatos passados (v.g. o precedente Doca Street, TJR..1, Ap. Civ. 200500154774, 19a CC, rel. des. Milton Fernandes de Souza, julg. 7.3.2006, em que se discutiu se a reconstituição, em programa de televisão, de crime de homicídio cometido pela parte que já havia cumprido pena, reavivando seu passado, violaria sua personalidade), cede frente ao interesse público inerente à publicação de biografias. Em doutrina, no elucidativo exemplo de Rodotà: "uma certa apresentadora de televisão, famosa pela atuação em programas infantis, quando era muito jovem, e por razões que não interessam, posou nua para um fotógrafo. Pode-se requerer que aquelas fotos não sejam publicadas invocando o direito ao esquecimento? Segundo nós sim, a menos que sejam essenciais para a informação, a exemplo do que ocorre quando se quer escrever uma biografia completa da pessoa" (Intervista su privacy e liberta, cit., p. 65; tradução livre). No original: "una certa presentatrice televisiva, ora famosa per i programmi per bambini, quando era giovanissima, e per ragioni che non ci interessano, posò nuda per un fotografo. Può chiedere che quelle foto o non vengano pubblicate invocando ii diritto all'oblio? Secondo noi si, a meno che non siano essenziali per l'infonnazione, ad esempio quando si vuol scrivere una completa biografia della persona".

${ }_{18}$ Neste particular, refira-se, exemplificativamente, ao caso Garrincha, no qual as herdeiras, a pretexto de proteger a honra e imagem do falecido, pleitearam indenização por dano moral e material, consistente em percentual na venda das biografias não autorizadas, a denotar a mercantilização da personalidade do retratado (STJ, REsp. 521697, 4a T., rel. min. Cesar Asfor Rocha, julg. 16.2.2006).
} 
teleológica porque o que tem em mente o constituinte, com a proteção da personalidade, não é o cerceamento das liberdades fundamentais, sendo certo que o interesse público torna publicáveis fatos verossímeis oferecidos pela vida privada dos personagens voluntários da história; dogmática porque, como visto, nem todos os danos são indenizáveis pelo ordenamento, incorrendo, em linha de princípio, ilicitude no exercício de liberdades fundamentais; e sistemática porque é imperativo ponderar as liberdades fundamentais com a tutela da personalidade, sendo ambos previstos pelo ordenamento jurídico que, necessariamente, há de ser unitário, sistemático e coerente. ${ }^{19}$

37. Em análise, a ponderação previa e in abstracto entre o direito fundamental à informação e as liberdades de expressão e de pensamento, de um lado, e a proteção à imagem, honra, privacidade e intimidade da pessoa pública biografada, de outro lado, não pode importar em sacrifício das primeiras, sob pena de se consagrar censura privada e a extinção do gênero biografia. Eventual dano causado só pela informação de fato considerado histórico não é ressarcível. Ainda que prejudicial à personalidade do biografado, trata-se de dano que não pode ser considerado injusto, por tutelar as liberdades de expressão, de pensamento e de informação, asseguradas pelo texto Constitucional.

38. O abuso ou desvio do exercício da liberdade de informação, caracterizado pela ilicitude das fontes, falsidade evidente dos fatos apresentados ou desvirtuamento da finalidade do interesse tutelado severamente punido pelo ordenamento, após juízo a posteriori (jamais a priori, mediante ponderação in abstracto que, in casu, constituiria censura privada, em constrangedora incompatibilidade com o texto constitucional), capaz de configurar numerosos tipos

\footnotetext{
${ }^{19}$ Na página clássica de Norberto Bobbio, “Ora, quando perguntamos se um ordenamento jurídico constitui um sistema, perguntamos se as normas que o compõem estão em relação de coerência entre elas, e em quais condições seja possível esta relação. (...) diz-se que um ordenamento jurídico constitui um sistema porque não podem nele coexistir normas incompatíveis. Aqui 'sistema' equivale a validade do princípio que exclui a incompatibilidade das normas" (Teoria dell'ordinamento giuridico. Torino: G. Giappichelli Editore, 1960. p. 69-80; tradução livre). No original: "(...) Orbene, quando ci chiediamo se un ordinamento giuridico costituisca un sistema, ci chiediamo se le norme che lo compongono siano in rapporto di coerenza tra loro, e a quali condizioni sia possibile questo rapporto. (...) si dice che un ordinamento giuridico costituisce un sistema perchè non possono coesistire in esso norme incompatibili. Qui 'sistema' equivale a validità del principio che esclude la incompatibilità delle norme". V., ainda, sobre o tema, PERLINGIERI, Pietro. Complessita e unitarieta dell'ordinamento giuridico vigente. In: Rassegna di diritto civile, vol. 1/05, Napoli: Edizone Scientifiche ltaliane, 2005. p. 192-195; e TEPEDINO, Gustavo. Normas constitucionais e direito civil na construção unitária do ordenamento. In: Temas de direito civil, 1. III. Rio de Janeiro: Renovar, 2009. p. 7-12.
} 
penais (calúnia, injúria, difamação, prática de racismo, falsidade ideológica etc...). Por evidente, conforme precedentes do Supremo Tribunal Federal, coibida seria a obra que, sob aparente conteúdo informativo, revelasse intuito imoral, criminoso ou doloso contra a honra, intimidade ou imagem do biografado.

39. Tal reação do ordenamento, no campo da responsabilidade civil, não decorre do simples impacto negativo causado pela notícia histórica na personalidade do biografado ou de sua família, ainda que tal fato lhes seja efetivamente desgostoso e sofrido, mas somente do desvirtuamento da liberdade de expressão, que caracterizaria mentira ou desinformação, a configurar invariavelmente conduta abusiva. Esta é a única hipótese, no âmbito da atividade jornalística e literária, em que a linguagem dos arts. 20 e 21 pode ser preservada do ponto de vista hermenêutico, compatibilizando os dispositivos ao texto constitucional: quando a publicação for considerada veículo de propósito criminoso ou doloso, para fins reprovados pelo ordenamento, de forma a descaracterizar a finalidade informativa.

\section{Resposta ao quesito}

À luz do ordenamento jurídico-constitucional brasileiro, a publicação ou veiculação de obras biográficas, literárias ou audiovisuais, de pessoas públicas, ou pessoas envolvidas em acontecimentos de interesse público, depende da autorização das pessoas biografadas ou envolvidas de qualquer forma na obra biográfica (ou de seus familiares, em caso de pessoas falecidas)?

Resposta: Não. A exigência de autorização do biografado ou de seus familiares (na hipótese de pessoa falecida) prévia à publicação de biografia representa intolerável violação às liberdades de informação, expressão e pensamento, constitucionalmente tuteladas, a configurar, a partir de ponderação in abstracto, censura privada, acarretando, inevitavelmente, a extinção do gênero biografia. Por isso mesmo, tal interpretação dos arts. 20 e 21 do Código Civil afigura-se inconstitucional, não podendo ser admitida.

As biografias revelam narrativas históricas descritas a partir de referências subjetivas, isto é, do ponto de vista dos protagonistas dos fatos que integram a história. Tais fatos, só por serem considerados históricos, já revelam seu interesse público, em favor da liberdade de informar e de ser informado, 
essencial não somente como garantia individual, mas como preservação da memória e da identidade cultural da sociedade.

Os danos sofridos pela personalidade dos biografados e de seus descendentes, quando a biografia se circunscreve aos limites de legitimidade próprios da informação constitucionalmente tutelada, isto é, quando baseada em fatos verossímeis obtidos por fontes legítimas e sem intuito abusivo ou doloso, não são danos ressarcíveis ou aptos a suscitarem a tutela preventiva de que cuidam os arts. 20 e 21 do Código Civil.

Por outro lado, o abuso ou desvio do exercício da liberdade de informação, caracterizados pela ilicitude das fontes, falsidade evidente dos fatos apresentados ou desvirtuamento da finalidade do interesse tutelado, é severamente punido pelo ordenamento, após juízo a posteriori, capaz de configurar, inclusive, tipos penais.

No campo da responsabilidade civil, o desvirtuamento da liberdade de expressão, por meio da veiculação de fatos mentirosos ou manipulados, configura conduta abusiva, sendo coibido pelo ordenamento jurídico.

Eis a única hipótese, no âmbito da atividade jornalística e literária, em que a linguagem dos arts. 20 e 21 do Código Civil pode ser preservada do ponto de vista hermenêutico, compatibilizando os dispositivos ao texto constitucional: quando a publicação for considerada veículo de propósito criminoso ou doloso, para fins reprovados pelo ordenamento, de forma a descaracterizar a finalidade informativa.

Rio de Janeiro, 15 de junho de 2012 